\title{
Glaciecola lipolytica sp. nov., isolated from seawater near Tianjin city, China
}

\author{
Li-Ping Chen, ${ }^{1,2}+$ Hai-Ying Xu, ${ }^{1,2}+$ Song-Zhe Fu, ${ }^{1,2}$ Hong-Xia Fan, ${ }^{1,2}$ \\ Ying-Hao Liu, ${ }^{1}$ Shuang-Jiang $\mathrm{Liu}^{1}$ and Zhi-Pei Liu ${ }^{1}$
}

Correspondence

Zhi-Pei Liu

liuzhp@sun.im.ac.cn
The genus Glaciecola was originally described to accommodate aerobic, psychrophilic, slightly halophilic bacteria and initially comprised two species, Glaciecola punicea and Glaciecola pallidula (Bowman et al., 1998). Both species were isolated from sea-ice diatom assemblage samples collected from coastal areas of eastern Antarctica. Since then, further species of the genus Glaciecola have been isolated from marine environments: Glaciecola mesophila (Romanenko et al., 2003) from marine invertebrates, Glaciecola polaris (Van Trappen et al., 2004) from Arctic Ocean seawater, Glaciecola nitratireducens (Baik et al., 2006) from coastal surface seawater, Glaciecola chathamensis (Matsuyama et al., 2006) from Pacific Ocean floor sediment and Glaciecola psychrophila (Zhang et al., 2006) and Glaciecola agarilytica (Yong et al., 2007) from East Sea sediments. Species of the genus Glaciecola show diverse physiological and biochemical properties, such as psy-

†These authors contributed equally to this paper.

The GenBank/EMBL/DDBJ accession number for the 16S rRNA gene sequence of strain $\mathrm{E}^{\top}$ is EU183316.

Transmission electron micrographs, 2D TLC of polar lipids and a comparison of fatty acid profiles are available as supplementary material with the online version of this paper. chrophily (G. punicea, G. pallidula and G. psychrophila), agar digestion (G. mesophila and G. agarilytica), nitrate reduction ( $G$. nitratireducens) and polysaccharide formation (G. chathamensis). Their wide distribution in marine environments and diversity of physiological properties suggest that they may play important roles in processes within marine ecosystems such as the degradation of agar and biogeochemical cycles of elements such as carbon and nitrogen.

In the course of our study on microbial diversity of coastal surface seawater near Tianjin city, China, an aerobic and heterotrophic, Gram-negative bacterium, strain $\mathrm{E} 3^{\mathrm{T}}$, was obtained that is phylogenetically related to members of the genus Glaciecola. In this communication, we describe the isolation and polyphasic taxonomic study of strain $\mathrm{E} 3^{\mathrm{T}}$.

A surface seawater sample was collected and diluted with sterilized $\mathrm{NaCl}$ solution $(2 \%, \mathrm{w} / \mathrm{v})$. For isolation, serially diluted samples were spread onto low-organic seawater medium (LOSWM) that contained $1.0 \mathrm{~g}$ peptone and $0.50 \mathrm{~g}$ yeast extract $(1 \text { distilled water })^{-1}$ with agar $(1.5 \%$, $\mathrm{w} / \mathrm{v})$ and incubated at $30{ }^{\circ} \mathrm{C}$ for 10 days. Individual colonies were picked up, cultured in LOSWM and stored at $-20{ }^{\circ} \mathrm{C}$ in $20 \%$ glycerol $(\mathrm{w} / \mathrm{v})$. Strain $\mathrm{E} 3^{\mathrm{T}}$ could also 
grow in marine broth $2216(\mathrm{MB})$ and on marine agar 2216 (MA) (both from Difco).

Cell morphology was examined by transmission electron microscopy (H600; Hitachi) and scanning electron microscopy (FEI QUANTA 200). Gliding motility was investigated as described by Dong \& Cai (2001). The Gram reaction was examined by staining cells grown on LOSWM plates at $30{ }^{\circ} \mathrm{C}$ for $24 \mathrm{~h}$ according to the method described by Gerhardt et al. (1994). Endospore formation was determined after malachite green staining (Dong \& Cai, 2001) of cells grown on LOSWM plates. Cells of strain $E 3^{\mathrm{T}}$ are Gram-negative, non-spore-forming rods $(0.4-0.5 \mu \mathrm{m}$ wide and $1.0-2.5 \mu \mathrm{m}$ long) and motile with a polar flagellum. Buds and prosthecae can be produced (see Supplementary Fig. S1, available in IJSEM Online), similarly to G. polaris (Van Trappen et al., 2004).

The 16S rRNA gene of strain $\mathrm{E} 3^{\mathrm{T}}$ was amplified using bacterial universal primers 27F and 1492R (Lane, 1991) and $16 \mathrm{~S}$ rRNA gene sequence alignment was performed with CLUSTAL_X (version 1.64b; Thompson et al., 1997). Database searches by using BLAST (Altschul et al., 1990) at NCBI indicated that strain $\mathrm{E} 3^{\mathrm{T}}$ was closely related to $G$. chathamensis and G. agarilytica, with 94.6 and $94.4 \% 16 \mathrm{~S}$ rRNA gene sequence similarity to the respective type strains. Phylogenetic trees were constructed by the neighbour-joining method (Saitou \& Nei, 1987) and the maximum-parsimony method (Fitch, 1971) in MEGA version 3.1 (Kumar et al., 2004). Strain $\mathrm{E} 3^{\mathrm{T}}$ formed a distinct phylogenetic lineage within the genus Glaciecola (Fig. 1), indicating that it was likely to represent a novel species of the genus Glaciecola.

The $\mathrm{pH}$ range for growth was determined in LOSWM that was adjusted to various $\mathrm{pH}$ values (initial $\mathrm{pH} 4.4-10$ at intervals of $0.2 \mathrm{pH}$ units) with $\mathrm{HCl}$ or $\mathrm{Na}_{2} \mathrm{CO}_{3}$. Growth at various temperatures $\left(0-40{ }^{\circ} \mathrm{C}\right)$ was measured on LOSWM plates. Sodium ion requirement and tolerance of $\mathrm{NaCl}$ were determined in $\mathrm{MB}$ with $\mathrm{NaCl}$ concentrations of $0-10.0 \%$

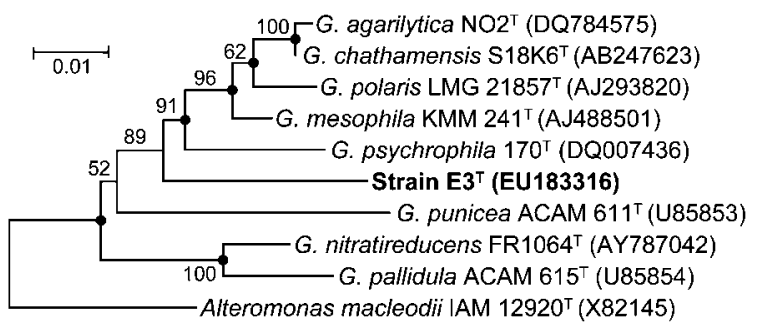

Fig. 1. Neighbour-joining phylogenetic tree based on the $16 \mathrm{~S}$ rRNA gene sequences of strain $E 3^{\top}$ and recognized species of the genus Glaciecola. Numbers at nodes represent percentages of bootstrap support of 1000 resampled datasets (values $>50 \%$ are shown). The sequence of Alteromonas macleodii IAM $12920^{\top}$ was used as an outgroup. Solid circles indicate that the corresponding nodes were also recovered in a maximum-parsimony tree (not shown). Bar, 0.01 substitutions per nucleotide position. (w/v, in increments of $0.5 \%)$. Anaerobic growth was determined in LOSWM in an anaerobic test tube gassed with nitrogen. Catalase activity was judged by formation of bubbles after a $3 \% \mathrm{H}_{2} \mathrm{O}_{2}$ solution was dropped onto a fresh colony. Oxidase activity and hydrolysis of casein, starch and Tweens 20, 40, 60 and 80 were determined as described by Dong \& Cai (2001) except that artificial seawater (ASW) was used instead of distilled water. The ASW contained (per litre distilled water) $23.6 \mathrm{~g} \mathrm{NaCl}$, $0.64 \mathrm{~g} \mathrm{KCl}, 4.53 \mathrm{~g} \mathrm{MgCl}_{2} \cdot 6 \mathrm{H}_{2} \mathrm{O}, 5.94 \mathrm{~g} \mathrm{MgSO}_{4} \cdot 7 \mathrm{H}_{2} \mathrm{O}$ and $1.3 \mathrm{~g} \mathrm{CaCl}_{2} \cdot 2 \mathrm{H}_{2} \mathrm{O}$ (Bruns et al., 2001). Acid production from carbohydrates was determined using API $50 \mathrm{CH}$ strips (bioMérieux), using a medium composed of $50 \% \mathrm{CHB} / \mathrm{E}$ medium (bioMérieux) with $0.075 \% \mathrm{CaCl}_{2} \cdot 2 \mathrm{H}_{2} \mathrm{O}, 1.875 \%$ $\mathrm{NaCl}$ and $0.375 \% \mathrm{MgCl}_{2}$. Carbohydrate assimilation was determined using API $50 \mathrm{CH}$ strips, using ASW supplemented with $0.05 \%$ yeast extract for resuspension of cells, and the strips were incubated at $30{ }^{\circ} \mathrm{C}$ for 2 weeks. The test strips were set up according to the manufacturer's instructions. Additional biochemical properties and enzyme activities were detected by API 20NE and API ZYM (bioMérieux) according to the manufacturer's instructions. Susceptibility to antibiotics was determined using filter-paper discs (Beijing Pharmaceutical Company) containing various antibiotics as specified in the species description. Phenotypic properties are given in Table 1 and in the species description. Several characteristics, including hydrolysis of gelatin, starch and agar, acid production from glucose and the utilization of several carbohydrates, differentiated strain $\mathrm{E} 3^{\mathrm{T}}$ from other species of the genus Glaciecola.

The cellular fatty acid profile was determined by using the MIDI Sherlock Microbial Identification System (Microbial ID) with cells grown on LOSWM plates at $30{ }^{\circ} \mathrm{C}$ for 3 days, according to the manufacturer's instructions. Fatty acids of strain E3 ${ }^{\mathrm{T}}(>1 \%)$ are summed feature $3\left(\mathrm{C}_{16: 1} \omega 7 c\right.$ and/or iso- $\left.\mathrm{C}_{15: 0} \quad 2-\mathrm{OH}\right) \quad(34.5 \%), \mathrm{C}_{18: 1} \omega 7 c \quad(17.3 \%), \mathrm{C}_{16: 0}$ $(17 \%), \mathrm{C}_{17: 1} \omega 7 c(5.0 \%), \mathrm{C}_{14: 0}(4.1 \%), \mathrm{C}_{12: 0}(3.5 \%)$, $\mathrm{C}_{17: 0}(3.4 \%), \mathrm{C}_{12: 0} 3-\mathrm{OH}(2.9 \%), \mathrm{C}_{12: 1} 3-\mathrm{OH}(2.1 \%)$, $\mathrm{C}_{15: 0}(1.8 \%)$ and $\mathrm{C}_{18: 0}(1.5 \%)$. The fatty acid composition of strain $\mathrm{E} 3^{\mathrm{T}}$ is similar to those of other species of the genus Glaciecola (Supplementary Table S1).

Polar lipids were examined by two-dimensional TLC and characterized with spray reagents specific for $\alpha$-glycols (periodate-Schiff), sugars ( $\alpha$-naphthol/sulfuric acid, anisaldehyde/sulfuric acid), free amino groups (ninhydrin) and phosphate (Zindzadze) (Ventosa et al., 1993). A $50 \%$ sulfuric acid solution was used to detect spots of all kinds of lipids (Fujii et al., 2003). Strain $\mathrm{E} 3^{\mathrm{T}}$ contains four polar lipids (Supplementary Fig. S2): large amounts of phosphatidylethanolamine and phosphatidylglycerol as its main phospholipids and small amounts of bis-phosphatidic acid and an unknown glycolipid. Phosphatidylethanolamine and phosphatidylglycerol are the major lipids reported for G. mesophila KMM $241^{\mathrm{T}}$ (Romanenko et al., 2003) and G. agarilytica LMG $23762^{\mathrm{T}}$ (Yong et al., 2007). Strain E3 ${ }^{\mathrm{T}}$ differentiated from G. mesophila KMM $241^{\mathrm{T}}$ and $G$. 
Table 1. Properties that differentiate strain $\mathrm{E} 3^{\top}$ from Glaciecola species

Species/strain: 1, strain E3 ${ }^{\mathrm{T}}$; 2, G. mesophila (data from Romanenko et al., 2003); 3, G. chathamensis (Matsuyama et al., 2006); 4, G. polaris (Van Trappen et al., 2004); 5, G. agarilytica (Yong et al., 2007); 6, G. punicea (Bowman et al., 1998); 7, G. pallidula (Bowman et al., 1998); 8, G. nitratireducens (Baik et al., 2006); 9, G. psychrophila (Zhang et al., 2006). +, Positive; -, negative; v, variable between strains, with the reaction for the type strain in parentheses; w, weak or delayed; ND, no data available. All species were positive for motility, sodium ion requirement for growth, oxidase and catalase and growth in $2-6 \%(\mathrm{w} / \mathrm{v}) \mathrm{NaCl}$.

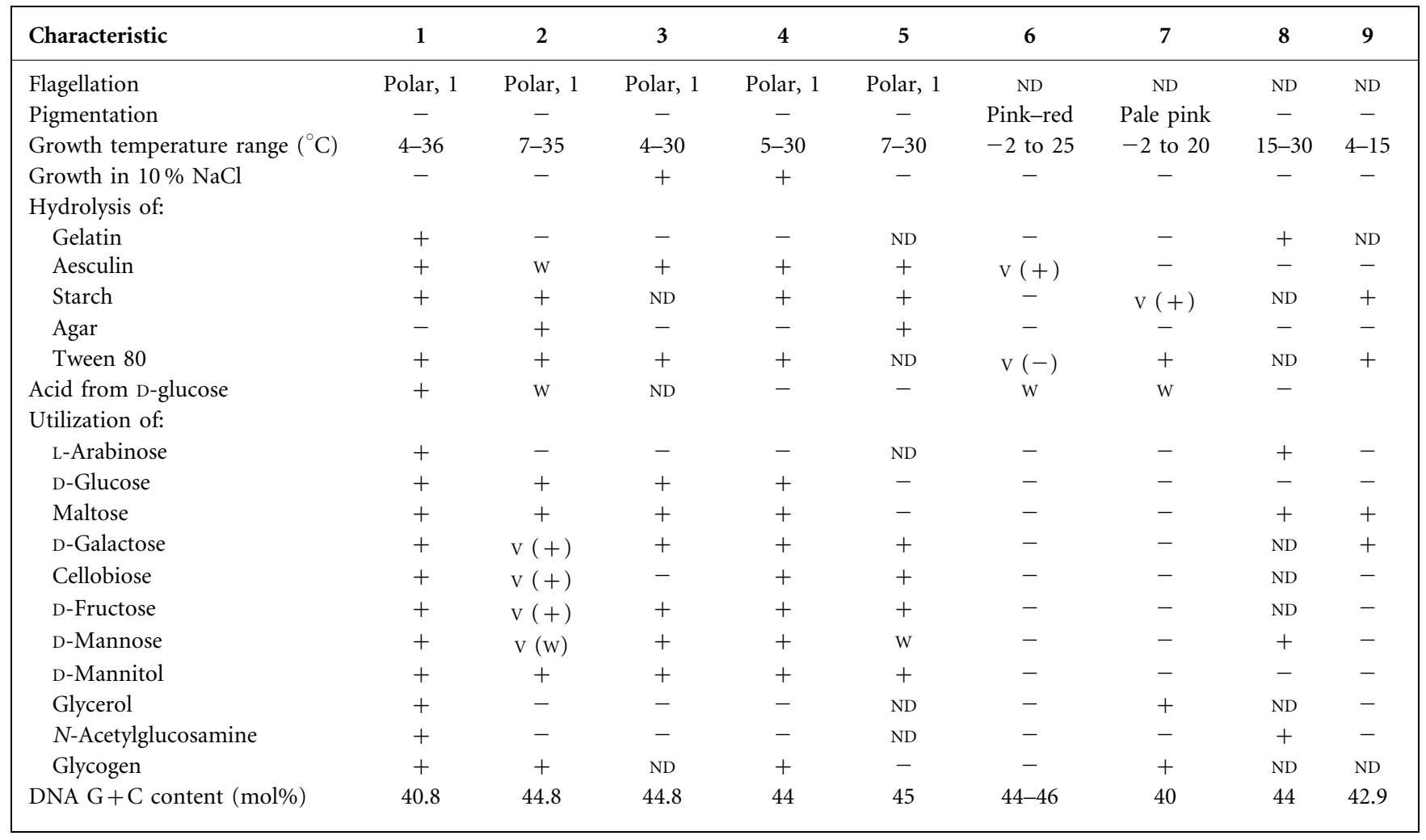

agarilytica LMG $23762^{\mathrm{T}}$ in the absence of diphosphatidylglycerol and the presence of unknown glycolipid GL1.

The $\mathrm{G}+\mathrm{C}$ content of genomic DNA was determined by thermal denaturation (Marmur \& Doty, 1962) with DNA from Escherichia coli $\mathrm{K}-12$ used as a control. The G+C content of strain $\mathrm{E} 3^{\mathrm{T}}$ was $40.8 \mathrm{~mol} \%$, a value that is within the range reported for the genus Glaciecola.

Based on the phenotypic and chemotaxonomic characteristics and phylogenetic analysis of the 16S rRNA gene sequence, we conclude that strain $\mathrm{E} 3^{\mathrm{T}}$ represents a novel species of the genus Glaciecola, for which we propose the name Glaciecola lipolytica sp. nov.

\section{Description of Glaciecola lipolytica sp. nov.}

Glaciecola lipolytica (li.po.ly'ti.ca. Gr. n. lipos fat; N.L. fem. adj. lytica from Gr. adj. lutikos - $\hat{e}$-on able to loosen, able to dissolve; N.L. fem. adj. lipolytica fat-dissolving, referring to the property of being able to hydrolyse lipid).

Exhibits the following properties in addition to those given in Table 1. Aerobic and heterotrophic. Cells are Gramnegative, non-spore-forming rods, $0.4-0.5 \mu \mathrm{m}$ wide and
$1.0-2.5 \mu \mathrm{m}$ long, motile with a polar flagellum. Forms non-pigmented colonies with a butyrous-mucoid consistency, about $2-4 \mathrm{~mm}$ in diameter on LOSWM plates after incubation at $30{ }^{\circ} \mathrm{C}$ for 2 days. Grows at $4-36{ }^{\circ} \mathrm{C}$ (optimum $30{ }^{\circ} \mathrm{C}$ ) but not at 0 or $40{ }^{\circ} \mathrm{C}$, at $\mathrm{pH} 7.0-9.0$ (optimum $\mathrm{pH} 7.6$ ) but not at $\mathrm{pH} 6.5$ or 9.5 and at $0.5-$ $9.0 \%(\mathrm{w} / \mathrm{v}) \mathrm{NaCl}$ (optimum $2 \%) . \mathrm{NaCl}$ is required for growth. Positive for oxidase, catalase, amylase, urease, nitrate reduction, $\mathrm{H}_{2} \mathrm{~S}$ production, arginine dihydrolase and hydrolysis of starch and lipid. Negative for indole production. Forms acid from D- and L-arabinose, D-xylose, methyl $\beta$-D-xylopyranoside, D-galactose, D-mannitol, $N$ acetylglucosamine, amygdalin, arbutin, aesculin, salicin, cellobiose, maltose, D-lactose, melibiose, sucrose, trehalose, inulin, raffinose, gentiobiose and D- and L-fucose. Does not form acid from glycerol, erythritol, D-ribose, L-xylose, Dadonitol, D-fructose, D-mannose, L-sorbose, L-rhamnose, dulcitol, inositol, D-sorbitol, methyl $\alpha$-D-mannopyranoside, methyl $\alpha$-D-glucopyranoside, melezitose, starch, glycogen, xylitol, turanose, D-lyxose, D-tagatose, D- or L-arabitol, potassium gluconate, potassium 2-ketogluconate or potassium 5-ketogluconate. Positive in tests for alkaline phosphatase, $\beta$-galactosidase, esterase lipase (C8), leucine 
arylamidase, valine arylamidase, cystine arylamidase, trypsin, acid phosphatase, naphthol-AS-BI-phosphohydrolase, $\alpha$-galactosidase and $N$-acetyl- $\beta$-glucosaminidase; tests negative for esterase (C4), lipase (C14), $\alpha$-chymotrypsin, $\beta$ galactosidase, $\beta$-glucuronidase, $\alpha$-glucosidase, $\beta$-glucosidase, $\alpha$-mannosidase and $\beta$-fucosidase. Utilizes Tweens 20 , 40, 60 and 80, D-ribose, D-xylose, methyl $\beta$-D-xylopyranoside, inositol, methyl $\alpha$-D-glucopyranoside, amygdalin, arbutin, aesculin, salicin, D-lactose, melibiose, sucrose, trehalose, inulin, melezitose, raffinose, starch, gentiobiose, potassium gluconate, potassium 2-ketogluconate, adipic acid, malic acid and trisodium citrate. No growth observed on erythritol, D-arabinose, L-xylose, D-adonitol, L-sorbose, L-rhamnose, dulcitol, D-sorbitol, methyl $\alpha$-D-mannopyranoside, capric acid, phenylacetic acid, xylitol, turanose, Dlyxose, D-tagatose, D- or L-fucose, D- or L-arabitol or potassium 5-ketogluconate. Resistant to ( $\mu \mathrm{g}$ per disc) carbenicillin (100), polymyxin B (300) and benzylpenicillin (10). Sensitive to neomycin (30), streptomycin (10), ampicillin (10), vancomycin (30), ciprofloxacin (5), rifampicin (5), chloramphenicol (30), kanamycin (30), erythromycin (15), norfloxacin (10), tetracycline (30), gentamicin (10) and novobiocin (5). Cells contain $\mathrm{C}_{16: 0}, \mathrm{C}_{18: 1} \omega 7 \mathrm{c}$ and summed feature $3\left(\mathrm{C}_{16: 1} \omega 7 \mathrm{c}\right.$ and/or iso- $\left.\mathrm{C}_{15: 0} 2-\mathrm{OH}\right)$ as the major fatty acids and phosphatidylethanolamine and phosphatidylglycerol as major polar lipids. The DNA $\mathrm{G}+\mathrm{C}$ content of the type strain is $40.8 \mathrm{~mol} \%$.

The type strain, $3^{\mathrm{T}}\left(=\mathrm{CGMCC} 1.7001^{\mathrm{T}}=\mathrm{JCM} 15139^{\mathrm{T}}\right)$, was isolated from coastal surface seawater near Tianjin city, China.

\section{Acknowledgements}

This work was supported by grants from the High-Tech Development Program of China (863 Program no. 2006AA100305).

\section{References}

Altschul, S. F., Gish, W., Miller, W., Myers, E. W. \& Lipman, D. J. (1990). Basic local alignment search tool. J Mol Biol 215, 403-410.

Baik, K. S., Park, Y.-D., Seong, C. N., Kim, E. M., Bae, K. S. \& Chun, J. (2006). Glaciecola nitratireducens sp. nov., isolated from seawater. Int J Syst Evol Microbiol 56, 2185-2188.

Bowman, J. P., McCammon, S. A., Brown, J. L. \& McMeekin, T. A. (1998). Glaciecola punicea gen. nov., sp. nov. and Glaciecola pallidula gen. nov., sp. nov.: psychrophilic bacteria from Antarctic sea-ice habitats. Int J Syst Bacteriol 48, 1213-1222.

Bruns, A., Rohde, M. \& Berthe-Corti, L. (2001). Muricauda ruestringensis gen. nov., sp. nov., a facultatively anaerobic, appendaged bacterium from German North Sea intertidal sediment. Int J Syst Evol Microbiol 51, 1997-2006.

Dong, X.-Z. \& Cai, M.-Y. (2001). Determinative Manual for Routine Bacteriology. Beijing: Scientific Press (English translation).

Fitch, W. M. (1971). Toward defining the course of evolution: minimum change for a specific tree topology. Syst Zool 20, 406-416.

Fujii, K., Satomi, M., Morita, N., Motomura, T., Tanaka, T. \& Kikuchi, S. (2003). Novosphingobium tardaugens sp. nov., an oestradioldegrading bacterium isolated from activated sludge of a sewage treatment plant in Tokyo. Int J Syst Evol Microbiol 53, 47-52.

Gerhardt, P., Murray, R. G. E., Wood, W. A. \& Krieg, N. R. (1994). Methods for General and Molecular Bacteriology. Washington, DC: American Society for Microbiology.

Kumar, S., Tamura, K. \& Nei, M. (2004). MEGA3: integrated software for molecular evolutionary genetics analysis and sequence alignment. Brief Bioinform 5, 150-163.

Lane, D. J. (1991). 16S/23S rRNA sequencing. In Nucleic Acid Techniques in Bacterial Systematics, pp. 115-175. Edited by E. Stackebrandt \& M. Goodfellow. Chichester: Wiley.

Marmur, J. \& Doty, P. (1962). Determination of the base composition of deoxyribonucleic acid from thermal denaturation temperature. $J$ Mol Biol 5, 109-118.

Matsuyama, H., Hirabayashi, T., Kasahara, H., Minami, H., Hoshino, T. \& Yumoto, I. (2006). Glaciecola chathamensis sp. nov., a novel marine polysaccharide-producing bacterium. Int J Syst Evol Microbiol 56, 2883-2886.

Romanenko, L. A., Zhukova, N. V., Rohde, M., Lysenko, A. M., Mikhailov, V. V. \& Stackebrandt, E. (2003). Glaciecola mesophila sp. nov., a novel marine agar-digesting bacterium. Int $J$ Syst Evol Microbiol 53, 647-651.

Saitou, N. \& Nei, M. (1987). The neighbor-joining method: a new method for reconstructing phylogenetic trees. Mol Biol Evol 4, 406425.

Thompson, J. D., Gibson, T. J., Plewniak, F., Jeanmougin, F. \& Higgins, D. G. (1997). The CLUSTAL_X windows interface: flexible strategies for multiple sequence alignment aided by quality analysis tools. Nucleic Acids Res 25, 4876-4882.

Van Trappen, S., Tan, T.-L., Yang, J., Mergaert, J. \& Swings, J. (2004). Glaciecola polaris sp. nov., a novel budding and prosthecate bacterium from the Arctic Ocean, and emended description of the genus Glaciecola. Int J Syst Evol Microbiol 54, 1765-1771.

Ventosa, A., Marquez, M. C., Kocur, M. \& Tindall, B. J. (1993). Comparative study of "Micrococcus sp." strains CCM 168 and CCM 1405 and members of the genus Salinicoccus. Int J Syst Bacteriol 43, 245-248.

Yong, J.-J., Park, S.-J., Kim, H.-J. \& Rhee, S.-K. (2007). Glaciecola agarilytica sp. nov., an agar-digesting marine bacterium from the East Sea, Korea. Int J Syst Evol Microbiol 57, 951-953.

Zhang, D.-C., Yu, Y., Chen, B., Wang, H.-X., Liu, H.-C., Dong, X.-Z. \& Zhou, P.-J. (2006). Glaciecola psychrophila sp. nov., a novel psychrophilic bacterium isolated from the Arctic. Int J Syst Evol Microbiol 56, 2867-2869. 